Dorijan F. Hajdu*

УДК 811.113.6'367.625

Nataša Ž. Ristivojević-Rajković

811.113.5'367.625

Univerzitet u Beogradu

ДОИ https://doi.org/10.18485/analiff.2017.29.2.1

Filološki fakultet

\title{
GLAGOLI MIŠLJENJA U ŠVEDSKOM I NORVEŠKOM JEZIKU IZ PERSPEKTIVE USVAJANJA OVIH JEZIKA KAO STRANIH
}

\begin{abstract}
Glagoli mišljenja predstavljaju važnu tematsku grupu u skandinavističkoj literaturi. Brojna kontrastivna istraživanja ovih glagola ukazuju na razlike u semantičkoj diferencijaciji polja mišljenja u skandinavskim jezicima i u većini drugih jezika. Kao poseban izazov u učenju skandinavskih jezika kao stranih ističe se glagolski par tro/tycka (švedski jezik) odn. tro/synes (norveški jezik), u kojem oba glagola izražavaju mišljenje govornika o nekom pitanju, ali se razlikuju po tome da li govornik o pomenutom pitanju poseduje neposredno, lično iskustvo ili ne. U radu se ispituje hipoteza o transferu iz maternjeg jezika kao osnovnom otežavajućem faktoru u učenju švedskog, odn. norveškog jezika kao stranog u slučaju studenata sa srpskim kao maternjim jezikom.
\end{abstract}

Ključne reči: glagoli mišljenja, švedski jezik, norveški jezik, usvajanje stranog jezika

\section{Uvod}

Glagoli mišljenja u skandinavskim jezicima u više navrata su istaknuti kao poseban izazov u učenju skandinavskih jezika kao stranih (Viberg 1980, Hasselgren 1993, Aijmer 1998, Chocholousova Fagertun 2016, Goddard \& Karlsson 2003). Kontrastivna analiza se mahom vrši sa odgovarajućom tematskom grupom glagola u engleskom jeziku, mada se navode i poređenja sa nekim drugim jezicima (holandski, nemački u Aijmer 1998, finski, grčki u Viberg 1980, češki u Chocholousova Fagertun 2016), pa se problematika specifičnog semantičkog diferenciranja ove tematske grupe u skandinavskim jezicima prepoznaje kao gotovo univerzalni pro-

Službena adresa: Filološki fakultet, Univerzitet u Beogradu, Studentski trg 3, 11000 Beograd. Elektronska adresa: dorijan.hajdu@fil.bg.ac.rs 
blem u učenju skandinavskih jezika kao stranih: "Varfor tycker vi oss t ex behöva de tre verben tycka - tänka - tro, när engelskan och rnånga andra språk oftast klarar sig med ett?"1 (Bolander 2001:16).

Interesovanje za ovu temu poteklo je iz našeg dugog iskustva u nastavi skandinavskih jezika na Filološkom fakultetu u Beogradu i čestog susretanja sa nepravilnom upotrebom skandinavskih glagola mišljenja kod studenata Skandinavistike. Zapitali smo se da li je razlog ovome transfer iz maternjeg jezika ili na usvajanje glagola mišljenja švedskog odn. norveškog jezika utiče i dužina učenja pomenutih jezika. Cilj nam je bio da ispitamo na koji način studenti švedskog odn. norveškog jezika upotrebljavaju glagole mišlje-

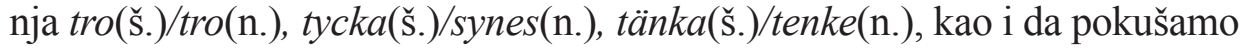
da utvrdimo faktore od kojih zavise odstupanja od pravilne upotrebe ovih glagola. Ispitivanje se zasniva na analizi odgovora informanata (studenata švedskog i norveškog jezika) na dve ankete sprovedene na Grupi za skandinavske jezike i književnosti Filološkog fakulteta u Beogradu.

\section{Tematska grupa glagola mišljenja u švedskom, norveškom i srpskom jeziku}

I pored toga što su švedski odn. norveški glagoli mišljenja prepoznati kao izazov pri učenju ova dva skandinavska jezika kao strana, u gramatikama švedskog odn. norveškog jezika nije im posvećena posebna pažnja. Oni se, pak, gotovo bez izuzetka pominju u udžbenicima namenjenim učenju švedskog odn. norveškog jezika. Prema ovim izvorima, semantički sadržaj glagola tro obuhvata elemente nesigurnosti i objektivnosti, upotrebljava se za tvrdnju u čiji sadržaj govornik nije sasvim siguran i čija se istinitost uglavnom može proveriti i izmeriti objektivnim kriterijumima. Takođe se koristi i za iskaze evaluativnog tipa u slučajevima u kojima govornik nema neposredno iskustvo o onome što predstavlja sadržaj iskaza²:

(1) (no.) Han tror det blir regn. 'Misli da će padati kiša.' (primer preuzet iz Ellingsen \& MacDonald 2004:143)

1 "Zašto smatramo da nam je npr. potrebno da imamo tri glagola tycka - tänka - tro, kada engleski i mnogi drugi jezici imaju samo jedan?"

2 Glagol tro se u oba ispitivana skandinavska jezika koristi i u značenju 'verovati' kao npr. u tro på Gud 'verovati u Boga'. 
(2) (no.) Jeg tror filmen er bra. 'Mislim da je film dobar.' (govornik nije gledao film, ali je čuo ili pročitao povoljnu kritiku filma) (primer preuzet iz Ellingsen \& MacDonald 2004:143)

(3) (̌̌v.) Jag tror att han har en brun överrock. 'Mislim da on ima jedan smed kaput.' (govornik nije siguran, iznosi pretpostavku) (primer preuzet iz Viberg, Ballardini, Stjärnlöf 1999: 142)

(4) (šv.) Jag tror att filmen är regiserad av Ingmar Bergman. 'Mislim da je film režirao Ingmar Bergman.'(v. pr. (2)).

(primer preuzet iz Viberg, Ballardini, Stjärnlöf 1999: 142).

Odgovarajući ekvivalenti na srpskom jeziku bili bi misliti i verovati.

Semantički sadržaj glagola tycka (̌̌v.) odn. glagol synes (no.) zasniva se na elementima evaluacije i subjektivnosti i koristi se pre svega za evaluativne iskaze kod kojih ispitivanje istinitosti sadržaja nije relevantno:

(5) (no.) Jeg synes du er en flink kokk. 'Mislim da si talentovan kuvar.' (primer preuzet iz Ellingsen \& MacDonald 2004:143)

(6) (no.) Hun synes filmen var god. 'Mislim da je film bio dobar.' (govornik je gledao film, tj. ima neposredno iskustvo), up. (̌̌v.) Hon tycker att filmen är bra.

(primer preuzet iz pregleda gramatike norveškog jezika koji prati udžbenik Det går bra (Lønn 2015), dostupno na: https:// norskfordeg.no/ressurser/det-gar-bra/grammatikk-2/)

(7 (̌̌v.) Jag tycker att Maria borde gå hem. 'Mislim da bi Marija trebalo da ide kući.'

(primer preuzet iz Viberg, Ballardini, Stjärnlöf 1999: 142)

Odgovarajući ekvivalenti na srpskom jeziku bili bi misliti i smatrati. Upotreba glagola tänka/tenke nije ilustrovana ni u gramatikama, ni u udžbenicima švedskog i norveškog jezika, ali se ovaj glagol često javlja u vežbanjima posvećenim utvrđivanju znanja o glagolima mišljenja skandinavskih jezika. Na osnovu informacija iz jednojezičnih rečnika švedskog i norveškog jezika, ekvivalenti ovog glagola na srpskom jeziku bili bi: misliti, razmišljati, nameravati, planirati.

Semantički sadržaj srpskog glagola misliti pokriva sva navedena značenja švedskih odn. norveških glagola mišljenj (up. odrednicu misliti u RMS). 


\section{Anketa - ispitanici i formalne odlike}

Anketu smo sproveli sa studentima druge i četvrte godine Grupe za skandinavistiku Filološkog fakulteta, sa švedskim odnosno norveškim jezikom kao glavnim predmetom. Anketa je bila podeljena u dva dela (ispitivanje je obavljeno u rasponu od dve nedelje). U prvom delu proveravana je praktična upotreba relevantnih glagola putem prevođenja sa srpskog na švedski i norveški jezik, dok su u drugom delu studenti pisali definicije ponuđenih švedskih odnosno norveških glagola (na srpskom jeziku). U prvom delu imali smo 55 ispitanika, od čega 27 studenta švedskog (17 sa druge, 10 sa četvrte godine studija) i 28 studenata norveškog (14 sa druge, 14 sa četvrte godine). U drugom delu ankete učestvovalo je ukupno 46 studenata, od toga 28 sa švedskog (14 sa druge, 14 sa četvrte godine), i 18 sa norveškog ( 8 sa druge, 10 sa četvrte godine).

U prvom delu ankete ispitanici su sa srpskog na švedski odnosno norveški jezik prevodili ukupno 26 rečenica koje su sadržale glagol misliti u značenjima pokrivenim trima švedskim odnosno norveškim glagolima (šv/ nor. tycka/synes, tro/tro, tänka/tenke). Rečenice u kojima se srpski glagol javljao u nekom od ova tri značenja bile su nasumično raspoređene. Raznovrsnosti radi, glagol se u primerima na srpskom javljao kako u prezentu, tako i u perfektu. Analizom vremena na švedskom i norveškom jeziku u prevodima rečenica u ovom radu se, međutim, nećemo detaljnije baviti, niti smo ih uzimali u obzir $u$ analizi rezultata istraživanja. Neki konkretni primeri rečenica na srpskom biće navedeni u sledećem poglavlju.

U drugom delu ankete su, pored tri aktuelna švedska i norveška glagola, bile ponuđene i druge tematske grupe glagola međusobno sličnog osnovnog značenja (v. odeljak 4). Ispitanici su zamoljeni da napišu opis značenja svih glagola koji su im poznati. Želeli smo da na taj način dođemo do sledećih praktičnih rezultata: (1) dobijanje odgovora najbližeg realnom nivou znanja ispitanika putem definisanja većeg broja glagola među kojima se nalaze i oni koji su nas u ovom istraživanju posebno zanimali, bez posebnog isticanja upravo tih glagola i (2) provera i postavljanje osnove za buduća istraživanja drugih tematskih grupa glagola, odnosno semantičkih polja (koje u ovom radu nećemo detaljnije obrađivati). Primera radi, neke od drugih tematskih grupa glagola bile su: šv/nor. betrakta/betrakte, ansel anse (sa osnovnim značenjem '(po)smatrati'); byta/bytte, förändralforan- 
dre, växla/veksle, skifte ('promeniti', 'zameniti'); gå/gå, åka/dra, köral kjøre ('ići peške', 'ići prevoznim sredstvom', 'voziti (se)'); lägga/legge, sätta/sette, ställa ('(po)staviti (u ležeći, sedeći, stojeći položaj)') i dr.

Razlog za pomenuti raspored delova empirijskog istraživanja jeste sledeći: smeštanjem provere upotrebe glagola u konkretnom kontekstu u prvi deo istraživanja želeli smo da dobijemo pravu sliku poznavanja praktične upotrebe bez prethodnog najavljivanja te provere putem pisanja definicija značenja glagola. Želeli smo da izbegnemo mogućnost stvaranja iskrivljene slike poznavanja praktične upotrebe glagola preko eventualnog uticaja koji bi prvobitno definisanje glagola i analiza značenja mogli imati na neposrednu praktičnu primenu u prevođenju. Na ovaj način verujemo da smo obezbedili verodostojnost podataka koje u ovom radu analiziramo kako praktičnog poznavanja kontekstualne upotrebe glagola na švedskom i norveškom jeziku (bez najave da će takva upotreba biti analizirana putem prethodnog ispitivanja definicija značenja ovih glagola), tako i poznavanja teorijskog značenja glagola kroz proveru više tematskih grupa glagola (bez isticanja samo one grupe koju u ovom radu obrađujemo).

Osnovna hipoteza kojom smo se vodili-zasnovana na dugogodišnjem iskustvu u radu na predmetu Savremeni skandinavski jezici G (švedski i norveški) - bila je da studenti u najvećoj meri poznaju tačne definicije ovih glagola (v. odeljak 2), ali da se prilikom praktične upotrebe javljaju problemi izazvani, pre svega, transferom iz srpskog jezika. Drugim rečima, pretpostavili smo da studenti u teoriji znaju u kom kontekstu se koristi koji glagol, ali da se u praksi javljaju problemi u njihovom odabiru. Činjenica, dakle, da glagol misliti kontekstualno pokriva sva tri polja značenja skandinavskih glagola i da se njime svi oni mogu prevesti na srpski jezik, otežava ispravnu upotrebu ova tri glagola u skandinavskim jezicima. Upotreba ovih glagola u neodgovarajućem kontekstu u švedskom i norveškom jeziku može dovesti do manjeg ili većeg nesporazuma ili prenošenja neželjene informacije, budući da se nekima od obrađivanih glagola nedvosmisleno iznose stavovi zasnovani na sopstvenom iskustvu, dok se drugima naglašava upravo odsustvo takvog iskustva (tyckal synes nasuprot tro). Uz ovo je važno napomenuti i činjenicu da izvorni govornici švedskog i norveškog jezika ne prave greške u odabiru glagola prema traženom značenju u određenom kontekstu i prilikom prenošenja konkretne (željene) poruke, pa se stoga pogrešna upotreba ne može podvesti ni pod eventualni ,svakodnevni, govorni jezik“. 
Pored toga, želeli smo da proverimo i napredak studenata na završnoj godini dodiplomskih studija po ovom pitanju, u odnosu na studente na drugoj godini. Zanimljivo je, u vezi s tim, bilo proveriti i odnos između ispravnosti definicija glagola u pomenutim grupama ispitanika.

\section{Analiza rezultata}

Osnovna hipoteza bila je, dakle, da glagol misliti, koji u srpskom jeziku pokriva sva tri polja značenja ispitivanih skandinavskih glagola, otežava njihovo ispravno korišćenje u švedskom i norveškom jeziku, uprkos tome što ispitanici dobro poznaju osnovna značenja pomenuta tri skandinavska glagola. Takođe smo hteli da proverimo hipotezu o dužini učenja, tj. o stepenu izloženosti švedskom odn. norveškom jeziku, kao potencijalnom faktoru u ispravnoj upotrebi ispitivanih glagola. Sva tri pitanja su, stoga, pokrivena anketom čije ćemo rezultate detaljno predstaviti u ovom odeljku.

\subsection{Poznavanje definicija}

Po pitanju osnovnih definicija glagola tycka/synes, tro/tro, tänkal toenke rezultati nedvosmisleno pokazuju da ispitanici odlično poznaju značenje ovih glagola. Detaljan pregled predstavićemo u tabeli (švedski jezik obeležen je sa „ک̌S“, norveški sa „,N“; naveden je procenat tačnih definicija glagola):

\begin{tabular}{|l|l|l|l|l|}
\hline \multirow{2}{*}{ Glagol } & \multicolumn{2}{|c|}{ II godina } & \multicolumn{2}{c|}{ IV godina } \\
\cline { 2 - 5 } & \multicolumn{2}{|c|}{ S } & $\mathrm{N}$ & \multicolumn{2}{c|}{$\mathrm{S}$} & $\mathrm{N}$ \\
\hline tycka/synes & $93 \%$ & $100 \%$ & $86 \%$ & $90 \%$ \\
\hline tro/tro & $100 \%$ & $100 \%$ & $93 \%$ & $90 \%$ \\
\hline tänka/tcenke & $100 \%$ & $87 \%$ & $93 \%$ & $90 \%$ \\
\hline
\end{tabular}

TABELA 1: Procenat tačnih definicija glagola po godini studija

Rezultati pokazuju da studenti druge godine studija imaju nešto viši procenat tačnih definicija, sa 100\% ispravnih odgovora u četiri od šest kategorija (jezik + glagol). Studenti četvrte godine takođe iskazuju odlično poznavanje značenja ovih švedskih i norveških glagola, sa tačnim definicijama u oko 90\% slučajeva u svim kategorijama. Svi glagoli prevođeni su, očekivano, i 
srpskim glagolom misliti, ali su za svaki glagol dodavani i dodatni glagoli ili objašnjenja. Tako su za glagole tycka/synes ispitanici pisali „smatrati“, „,iskustvo“, „lični stav“ i „,biti uveren“, za tro/tro „verovati“, „,ne biti siguran“, „,bez iskustva“, ,predosećati“, „,mišljenje bez stava“, a za tänka/tcenke ,razmišljati“ i ,planirati““. Ovako definisani i objašnjeni skandinavski glagoli ukazuju na to da su ispitanici u potpunosti upoznati sa osnovnim značenjima ovih glagola, odnosno s tim u kom se delu spektra značenja glagola misliti oni nalaze (u kojim kontekstima se koriste i sa kakvom namerom).

Nešto niži procenat tačnih definicija kod studenata četvrte godine dodiplomskih studija, ukoliko se o njemu može govoriti, verovatno bi se mogao objasniti činjenicom da su studenti druge godine skorije bili u kontaktu sa samim definicijama ovih glagola, preko predavanja u drugom semestru prve godine studija, na kojima se, između ostalog, detaljno upoznaju upravo s njihovim značenjem.

Opšti zaključak je, ipak, da svi ispitanici poseduju odlično teorijsko znanje o značenju ovih glagola i definišu ih ispravno u izuzetno visokom procentu, a često i u punih sto odsto.

\subsection{Praktična primena}

Po pitanju praktične primene teorijskih znanja - prevoda srpskih rečenica na švedski odnosno norveški jezik - javljaju se nešto drugačiji rezultati u odnosu na prethodnu kategoriju. Naime, u ovom aspektu nešto bolje rezultate beleže studenti četvrte godine studija. U ovom delu ankete, kao što smo rekli, ispitanici su prevodili 26 rečenica sa srpskog na švedski, odn. norveški jezik. Sve rečenice na srpskom jeziku sadržale su glagol misliti (u prezentu ili perfektu; lice je variralo) i izabrane su tako da obuhvate (nasumičnim redosledom) razne značenjske aspekte svakog od proveravanih glagola u švedskom i norveškom. Ukupni rezultati su sledeći: na drugoj godini studija, ispitanici beleže $60 \%$ tačnih odgovora (64\% na švedskoj, 56\% na norveškoj strani), dok na četvrtoj godini studija imamo rezultat od 73\% (77\% na švedskoj, $70 \%$ na norveškoj strani). U narednom

delu detaljno ćemo analizirati ove rezultate prema skandinavskom glagolu koji po značenju odgovara jednom od užih značenja srpskog glagola misliti. 


\subsubsection{Misliti kao tycka/synes}

Analizu rezultata počećemo glagolom misliti u značenju „smatrati“, odnosno od švedskog glagola tycka i norveškog synes. Primera sa glagolom misliti u ovom značenju u anketi bilo je ukupno sedam. Razlike u procentu tačnih prevoda između skandinavskih glagola prilično su male, ali vredi napomenuti da glagol tycka/synes ipak beleži najviši procenat tačnih odgovora - 69\% ukupno. Posebno je zanimljiva činjenica da su ispitanici sa oba jezika i sa obe godine studija zabeležili praktično identičan rezultat (samo studenti druge godine švedskog imaju jedan procenat tačnih odgovora više, dakle, $70 \%$ ). Ovde se, dakle, može govoriti o jednakom stepenu povezivanja određenog aspekta značenja glagola misliti sa odgovarajućim skandinavskim glagolom na obe proveravane godine studija. Ono što je, takođe, važno podvući jeste da su netačni odgovori u preko $90 \%$ slučajeva sadržali glagol tro/tro.

\subsubsection{Misliti kao tro/tro}

Rečenica sa glagolom misliti u značenju „verovati“ (v. odeljak 4.1 i druge ponuđene definicije) bilo je trinaest. Ovaj glagol, donekle očekivano, beleži najniže rezultate kod ispitanika oba jezika, ukupno 64\%. Od toga, studenti druge godine ga tačno primenjuju u $57 \%$ slučajeva $(59 \%$ na švedskom, $56 \%$ na norveškom), a studenti četvrte godine u $72 \%$ slučajeva (sa praktično istim procentom na oba jezika). Ovde, dakle, imamo i veću razliku između mlađih i starijih ispitanika - 15\% u korist studenata četvrte godine. Slično kao i sa prethodnim glagolima, pogrešni odgovori su u gotovo 100\% slučajeva sadržali glagol tycka/synes. Jasno je, dakle, da je razlika u značenju ovog para skandinavskih glagola ono što studentima švedskog odnosno norveškog zadaje najviše problema - u otprilike jednoj trećini slučajeva kod oba glagola.

\subsubsection{Misliti kao tänkaltenke}

Glagol misliti u značenju 'razmišljati' ili 'planirati' javio se u šest rečenica $u$ anketi. Rezultati u ovoj kategoriji specifični su iz nekoliko razloga. Tačnih odgovora u ovoj kategoriji bilo je ukupno 67\%. Ispitanici sa druge godine studija tačno ga upotrebljavaju u 56\% slučajeva $(68 \%$ 
na švedskom, 44\% na norveškom), dok oni sa četvrte beleže čak 78\% (93\% na švedskom, 63\% na norveškom). Kao što se iz navedenih rezultata vidi, kod ovog glagola imamo najveće razlike između godina studija, ali i između studenata dva jezika. Naime, studenti švedskog jezika glagol tänka ispravno primenjuju u izuzetno visokih $80 \%$ slučajeva, dok studenti norveškog ekvivalentni glagol tenke tačno koriste u tek 53\% situacija. Od toga, kod ispitanika na drugoj godini studija norveškog jezika beležimo ispod 50\% uspešnosti prevoda glagola misliti ovim norveških glagolom. Gotovo svi pogrešni odgovori studenata norveškog jezika tiču se upotrebe glagola tenke u značenju 'planirati' (rečenice Mislio sam da ispričam nekoliko viceva. Mislio sam da te podsetim na obećanje. Mislio sam da izvedem psa u šetnju. Mislim da već sutra rezervišem kartu. i Mislio sam da kupim automobil.), dok je rečenica u kojoj je glagol tenke upotrebljen u svom primarnom značenju, 'razmišljati', prevedena tačno u najvećem broju slučajeva. Pretpostavljamo da su studenti, kroz predavanja i vežbanja usmereni da se fokusiraju na značenje opšte upotrebe uma, oličeno u glagolu tenke, i da ga razlikuju od značenja iskazivanja mišljenja o nekome ili nečemu, tipičnog za glagole tro i synes, donekle zapostavili mogućnost upotrebe glagola tenke u značenju 'planirati', 'nameravati'. Ono što je, takođe, veoma zanimljivo jeste približno jednaka raspodela druga dva glagola u pogrešnim rezultatima ispitanika (tycka/synes prednjači nad tro/ tro sa oko $60 \%$ netačnih odgovora sa ovim glagolom).

\section{Zaključak}

Švedski odn. norveški glagoli mišljenja, tro/tro, tycka/synes, tänka/ tenke, prepoznati su u skandinavističkoj literaturi kao deo leksikona koji učenicima ovih skandinavskih jezika kao stranih predstavlja poseban izazov. Kao glavni faktor koji otežava učenje ovih glagola navode se razlike u semantičkoj diferencijaciji polja mišljenja između skandinavskih i većine drugih jezika: semantički obuhvat tri pomenuta švedska odn. norveška glagola odgovara samo jednom glagolu mišljenja u brojnim drugim jezicima. Analizom odgovora informanata, studenata švedskog i norveškog jezika, utvrdili smo da je transfer iz maternjeg jezika, u kojem se sva tri analizirana švedska odn. norveška glagola mogu prevesti samo jednim glagolom, misliti, presudan kad je reč o greškama u upotrebi glagola mišljenja 
u skandinavskim jezicima. Donekle različit procenat grešaka među studentima švedskog odn. norveškog jezika može se objasniti pojačanim fokusiranjem u nastavi norveškog na značenje razmišljanja kao procesa kod glagola tenke, i samim tim, zapostavljanjem ostalih značenja ovog glagola. Sistematska zamena glagola tycka/synes glagolom tro i obratno u pogrešnim odgovorima studenata obe godine i oba jezika, a ne glagolom tänka/tenke, ukazuje na činjenicu da upravo glagoli tycka/synes i tro dele prostor samo jednog od sekundarnih značenja srpskog glagola misliti, 'imati mišljenje o nekome ili nečemu', dok se glagol tänka/tenke može smatrati ekvivalentom nekih drugih značenja srpskog misliti: 'razmišljati', 'upućivati nekome misli', 'nameravati'. Poređenjem rezultata studenata druge godine sa rezultatima studenata četvrte godine, potvrđeno je da je za ispravnu praktičnu upotrebu ovih glagola značajnija izloženost jeziku koji se uči od teorijskog znanja o njihovom značenju. Uprkos tome što je teorijsko znanje studentima druge godine ,svežije“, i oni u tom segmentu pokazuju nešto bolje rezultate od studenata četvrte godine, studenti koji duže uče švedski odn. norveški pokazuju veću sigurnost u praktičnoj upotrebi skandinavskih glagola mišljenja.

\section{Literatura}

\section{Primarna literatura}

Lønn, Cecilie (2015). Nå begynner vi. Grunnbok. Fagbokforlaget, Bergen.

Lønn, Cecilie (2015). Nå begynner vi. Arbeidsbok. Fagbokforlaget, Bergen.

Lønn, Cecilie: Grammatikk (prati udžbenik Det går bra). Dostupno na: https:// norskfordeg.no/ressurser/det-gar-bra/grammatikk-2/

Viberg, A, K. Ballardini, S. Stjärnlöf. (1999). Svensk gramatik. Bokförlaget Natur och Kultur, Stockholm

Vujanić, Milica i dr. (ur.) (2007) Rečnik srpskoga jezika Matice srpske (RMS). Matica srpska, Novi Sad.

\section{Sekundarna literatura}

Aijmer, Karin (1998) "Epistemic predicates in contrast" U: Stig Johansson, Signe Oksefjell (eds.) Corpora and Cross-linguistic Research: Theory, Method and Case Studies. 
Bolander, Maria (2012). Funktionell svensk grammatik. Liber, Stockholm.

Chocholousova Fagertun, Bohumila Mia (2016). "Norwegian synes and tro and Their English Translations." Brünner Beiträge zur Germanistik und Nordistik 30 / 2016 / 1.

Goddard, Cliff \& Susanna Karlsson (2003). "Re-thinking THINK: Contrastive Semantics of Swedish and English". Proceedings of the 2003 Conference of the Australian Linguistic Society.

Viberg, Åke (1980). Tre semantiska fält i svenskan och några andra språk. SSM Report7, Projektet Svenska som målspråk, Stockholms universitet.

Dorijan Hajdu

Nataša Ristivojević-Rajković

\section{Summary \\ VERBS OF THINKING IN SWEDISH AND NORWEGIAN FROM PERSPECTIVE OF LANGUAGE ACQUISITION}

Verbs of thinking are an important thematic group in studies on Scandinavian languages. Numerous contrastive studies of these verbs indicate differences in the semantic differentiation of the semantic field of thought in the Scandinavian languages and in most other languages. A special challenge in learning Scandinavian languages as foreign is the verbal pair tro / tycka (Swedish) tro / synes (Norwegian), which both express the opinion of the speaker, but differ in whether the speaker has a personal experience of the phenomenon he/she is talking about or not. The paper examines the hypothesis of transfer from Serbian as mother tongue as the basic aggravating factor in the learning of Swedish or Norwegian as a foreign language.

Key words:verbs of thinking, Swedish, Norwegian, language acquisition 